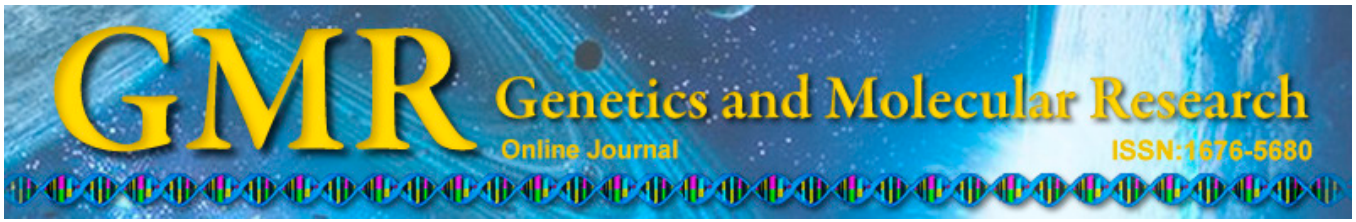

\title{
Analysis of genetic diversity identified by amplified fragment length polymorphism marker in hybrid wheat
}

\author{
M. Ejaz ${ }^{1 *}$, Z. Qidi ${ }^{1,2 *}$, Z. Gaisheng ${ }^{1}$, N. Na ${ }^{1}$, Z. Huiyan $^{1}$ and W. Qunzhu ${ }^{1}$ \\ ${ }^{1}$ Key Laboratory of Crop Heterosis, College of Agronomy, \\ Northwest A\&F University, \\ National Yangling Agricultural Biotechnology \& Breeding Center, \\ Yangling Branch of State Wheat Improvement Center, \\ Wheat Breeding Engineering Research Center, Ministry of Education, \\ Shaanxi Province, Yangling, China \\ ${ }^{2}$ College of Life Science, Henan Institute of Science and Technology, \\ Xinxiang, Henan Province, China \\ *These authors contributed equally to this study. \\ Corresponding author: Z. Gaisheng \\ E-mail: zhanggsh58@aliyun.com \\ Genet. Mol. Res. 14 (3): 8935-8946 (2015) \\ Received February 25, 2015 \\ Accepted June 7, 2015 \\ Published August 7, 2015 \\ DOI http://dx.doi.org/10.4238/2015.August.7.2
}

\begin{abstract}
Amplified fragment length polymorphism markers were used to assess genetic diversity in 10 male sterile wheat crop lines (hetero-cytoplasm with the same nucleus) in relation to a restorer wheat line. These male sterile lines were evaluated using 64 amplified fragment length polymorphism primer combinations, and 13 primers produced polymorphic bands, generating a total 682 fragments. Of the 682 fragments, 113 were polymorphic. The polymorphic information content and marker index values demonstrated the utility of the primer combinations used in the present study. Unweighted pair group method with arithmetic mean and principal coordinate analysis of the genotypic data revealed clustering of accessions based on genetic relationships, and accessions were separated into 2 groups with their restorer line.
\end{abstract}


Jaccard's similarity coefficient values suggested good variability among the male sterile lines, indicating their utility in breeding programs. The fallouts of analysis of molecular variance showed large within-group population variation, accounting for $77 \%$ of variation, while amonggroup comparison accounted for $23 \%$ of the total molecular variation, which was statistically significant. The molecular diversity observed in this study will be useful for selecting appropriate accessions for plant improvement and hybridization through molecular-breeding approaches and for developing suitable conservation strategies.

Key words: AFLP marker; Genetic diversity; Male sterile lines; Triticum aestivum

\section{INTRODUCTION}

As 1 of the 3 major cereal crops in the world, wheat is very important in food security and economic development. To meet the demand for the development of high-yielding and stress-resistant wheat cultivars, the genetic base of this crop must be increased. Improved wheat productivity through breeding platforms is based on the availability of genetic variability in elite wheat material. Variability in the bread wheat gene pool is grossly insufficient for addressing current and future breeding objectives. Parental selection is the most important step in the development of new cultivars. Efficient identification of superior hybrid combinations is a fundamental issue in wheat-breeding programs (Gowda et al., 2010). The efficiency of hybrid-breeding programs may be significantly enhanced if superior crosses can be predicted before field evaluation. The advancement of molecular techniques and biometric methods has allowed for the development of unique procedures for evaluating genetic variability. Analysis of genetic distance is a supplementary tool that is commonly used in breeding programs and is an important link between conservation and use of available genetic resources. Among the methods used to quantify genetic distances are morphological and molecular markers as well as pedigree information (Yadav et al., 2007). Hybridization of wheat in breeding involves the selection of diverse genotypes depending on whether the end product is a pure line or a hybrid variety. In this regime, efforts have also been made to predict the probability of developing superior genotypes from a cross by measuring genetic similarity or genetic distance between the parents, as the latter can be used to assess expected genetic variances in different sets of segregating progenies derived from different crosses. Knowledge of the genetic diversity arrays within breeding line population can improve the efficiency of gain through selection. The allopolyploid nature of bread wheat enables the introgression of genes from wild species by the recombination of homologous chromosomes (Valkoun, 2001). Wild relatives and related species can be successfully crossed with bread wheat (Arzani et al., 2000). Wild relative genes can be introgressed in cultivated wheat through recombination of homologous chromosomes, and undesirable gene linkages can be broken by repeated backcrossing to cultivated wheat. Interspecific crosses between tetraploid wheat and Aegilops species, as their close relatives, are useful for introducing desirable characters into bread wheat.

DNA-based molecular markers are useful both for quantifying genetic diversity within plant species and for detecting and characterizing closely related genotypes (Jasieniuk and Maxwell, 2001). Polymorphisms or DNA sequence differences are commonly analyzed to evaluate genetic similarity between and within populations of accessions (Lee, 1995). Several types of 
molecular markers are available; however, amplified fragment length polymorphism (AFLP) markers show several advantages, such as reproducibility, high levels of polymorphism that can be detected in a single reaction, the genome-wide distribution of markers, and no need for prior DNA sequence information compared with other DNA-based markers (Vos et al., 1995). AFLP analysis involves selective amplification of a subset of restriction enzyme-digested DNA fragments to generate a unique fingerprint of a particular genome (Mueller and Wolfenbarger, 1999). AFLP has been widely used to discriminate between different accessions of a number of plants species, including the common wheat Triticum aestivum L. (Almanza-Pinzón et al., 2003).

In this study, we determined the level of genetic variability and diversity among a sample of male sterile lines of wheat accessions using AFLP markers at the Key Laboratory of Crop Heterosis of Shaanxi Province, Northwest Agricultural \& Forest University, Yangling, China.

\section{MATERIAL AND METHODS}

In this study, male sterile lines $[\mathrm{ms}(\mathrm{K})-77(2), \mathrm{ms}(\mathrm{V})-77(2), \mathrm{ms}(\mathrm{Ven})-77(2), \mathrm{ms}(\mathrm{B})-$ $77(2), \mathrm{ms}(\mathrm{S})-77(2)]$ were divided into 2 groups based on their fertile maintainer line [A-90-110 and A-8222] of common wheat (T. aestivum); all lines contained hetero-cytoplasm with the same nucleus (Table 1). These sterile lines were derived from recurrent backcross after 20 generations. The seeds were soaked in water for $6 \mathrm{~h}$, after which the sprouted wheat seeds were grown in plastic pots over a period of 3 weeks at room temperature using stander agronomic culture practices.

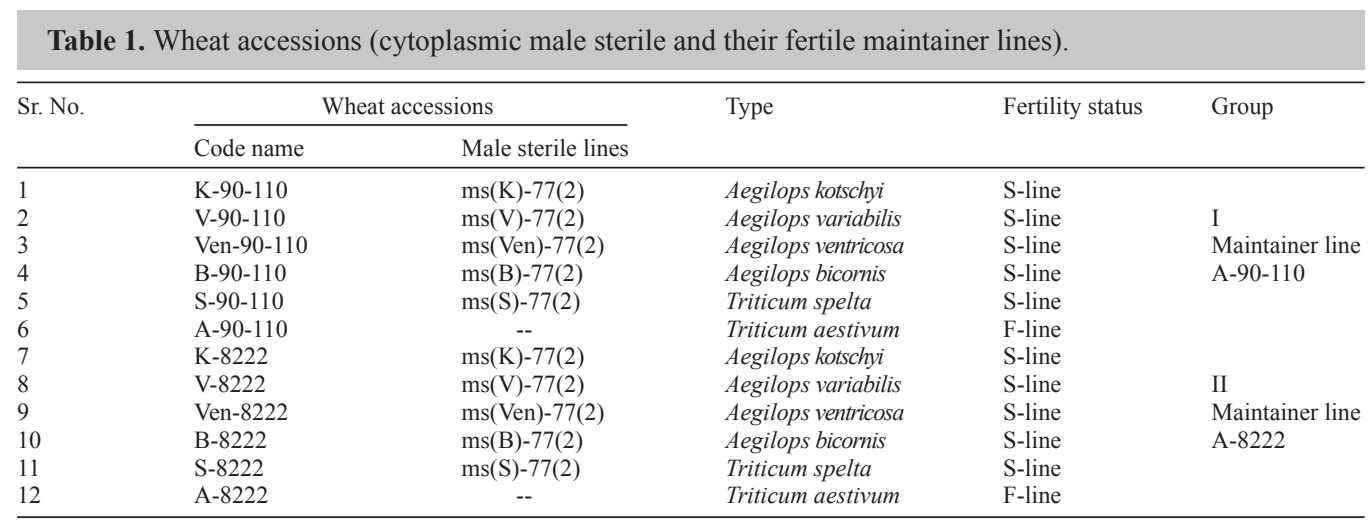

Wheat accessions are divided into two groups (Group I and Group II) based on their fertile maintainer line, Aegilops.

\section{DNA isolation}

First, $0.5 \mathrm{~g}$ fresh leaf material was harvested from 3-week-old seedlings from each line. DNA isolation was carried out using the method described by Doyle and Doyle (1990), with some modifications. Leaf material in extraction buffer (100 mM Tris-HCl, pH 8.0, $20 \mathrm{mM}$ EDTA, pH 8.0, $1.4 \mathrm{M} \mathrm{NaCl}, 2 \%(\mathrm{w} / \mathrm{v}) \mathrm{CTAB}, 1 \%(\mathrm{w} / \mathrm{v})$ polyvinylpyrrolidone and $2 \% \beta$-mercaptoethanol) was ground in liquid nitrogen and then incubated at $65^{\circ} \mathrm{C}$ for 60 min. Purification steps were carried out once with phenol:chloroform:isoamylalcohol (25:24:1) and twice with chloroform:isoamylalcohol (24:1). RNA was digested by RNase enzyme and incubated at $37^{\circ} \mathrm{C}$ for $30 \mathrm{~min}$. The DNA was pelleted using ice cold anhydrous ethanol and $1 / 10$ th volume $3 \mathrm{M} \mathrm{CH}_{3} \mathrm{COONa}$ and then incubated at $-70^{\circ} \mathrm{C}$ for $60 \mathrm{~min}$ before centrifugation at $12,000 \mathrm{rpm}$ for $15 \mathrm{~min}$ at $4^{\circ} \mathrm{C}$. This was followed by a $70 \%$ ethanol 
wash; the pellets were air-dried and resuspended in $0.2 \mathrm{~mL} 1 \mathrm{X}$ Tris-EDTA buffer, $\mathrm{pH}$ 8.0. The recovered DNA was quantified fluorometrically on a $1.5 \%$ agarose gel using ethidium bromide staining.

\section{AFLP marker}

The AFLP marker (Vos et al., 1995) as modified by Pillay and Myers (1999) was used. All 64 primers were used to examine genetic diversity (Table 2). Next, $200 \mathrm{~g}$ DNA was digested with EcoRI and $M s e$ RI (Thermo Scientific, Waltham, MA, USA) at $37^{\circ} \mathrm{C}$ for $5 \mathrm{~h}$ and $8^{\circ} \mathrm{C}$ for $4 \mathrm{~h}$. The digested samples were incubated at $70^{\circ} \mathrm{C}$ for $15 \mathrm{~min}$ to inactivate the restriction endonucleases. EcoRI and MseRI adapters were ligated to the digested DNA samples to produce a template DNA for amplification. Pre-amplification was carried out using the primers E00 and M00 and $1 \mu \mathrm{L}$ of each resonant selective nucleotide (Table 3 ) in a thermo-cycler for 32 cycles set at $94^{\circ} \mathrm{C}$ denaturation for $30 \mathrm{~s}, 56^{\circ} \mathrm{C}$ annealing for $45 \mathrm{~s}$, and $72^{\circ} \mathrm{C}$ extension for $2 \mathrm{~min}$. Initial denaturation was conducted at $94^{\circ} \mathrm{C}$ for $2 \mathrm{~min}$ and the final extension was conducted at $72^{\circ} \mathrm{C}$ for $10 \mathrm{~min}$. The amplification products were diluted 20 -fold in TE buffer and stored at $-20^{\circ} \mathrm{C}$. Selective AFLP was conducted using $1 \mu \mathrm{L}$ of each EcoRI and MseI primers, $5 \mu \mathrm{L}$ diluted polymerase chain reaction (PCR) products from the pre-amplification, $3 \mu \mathrm{LddH}_{2} \mathrm{O}$, and $10 \mu \mathrm{L}$ master mix.

\begin{tabular}{|c|c|c|c|c|c|c|c|}
\hline $\mathrm{E} 1 / \mathrm{M} 1$ & E1/M2 & E1/M3 & E1/M4 & E1/M5 & E1/M6 & E1/M7 & E1/M8 \\
\hline E2/M1 & E2/M2 & E2/M3 & $\mathrm{E} 2 / \mathrm{M} 4$ & E2/M5 & E2/M6 & E2/M7 & E2/M8 \\
\hline E3/M1 & E3/M2 & E3/M3 & E3/M4 & E3/M5 & E3/M6 & E3/M7 & E3/M8 \\
\hline E4/M1 & $\mathrm{E} 4 / \mathrm{M} 2$ & E4/M3 & E4/M4 & E4/M5 & E4/M6 & $\mathrm{E} 4 / \mathrm{M} 7$ & $\mathrm{E} 4 / \mathrm{M} 8$ \\
\hline E5/M1 & $\mathrm{E} 5 / \mathrm{M} 2$ & E5/M3 & E5/M4 & E5/M5 & E5/M6 & E5/M7 & E5/M8 \\
\hline E6/M1 & E6/M2 & E6/M3 & E6/M4 & E6/M5 & E6/M6 & E6/M7 & E6/M8 \\
\hline E7/M1 & E7/M2 & E7/M3 & E7/M4 & E7/M5 & E7/M6 & E7/M7 & E7/M8 \\
\hline E8/M1 & E8/M2 & E8/M3 & E8/M4 & E8/M5 & E8/M6 & E8/M7 & E8/M8 \\
\hline
\end{tabular}

Table 3. Amplified fragment length polymorphism primer sequence.

\begin{tabular}{ll}
\hline Code & Primer sequence \\
\hline EAF & 5'-CTC GTA GAC TGC GTA CC-3' \\
EAR & 5'-AAT TGG TAC GCA GTC TAC-3' \\
MAF & 5'-GAC GAT GAG TCC TGA G-3' \\
MAR & 5'-TAC TCA GGA CTC AT-3' \\
E00 (pre-amplifier primer) & 5'-GTA GAC TGC GTA CCA ATTC A-3' \\
M00 (pre-amplifier primer) & 5'-GAC GAT GAG TCC TGA GTAA C-3' \\
E01 & 5'-GTA GAC TGC GTA CCA ATTC AAC-3' \\
E02 & 5'-GTA GAC TGC GTA CCA ATTC AAG-3' \\
E03 & 5'-GTA GAC TGC GTA CCA ATTC ACA-3' \\
E04 & 5'-GTA GAC TGC GTA CCA ATTC ACT-3' \\
E05 & 5'-GTA GAC TGC GTA CCA ATTC ACC-3' \\
E06 & 5'-GTA GAC TGC GTA CCA ATTC ACG-3' \\
E07 & 5'-GTA GAC TGC GTA CCA ATTC AGC-3' \\
E08 & 5'-GTA GAC TGC GTA CCA ATTC AGG-3' \\
M01 & 5'-GAC GAT GAG TCC TGA GTAA CAA-3' \\
M02 & 5'-GAC GAT GAG TCC TGA GTAA CAC-3' \\
M03 & 5'-GAC GAT GAG TCC TGA GTAA CAG-3' \\
M04 & 5'-GAC GAT GAG TCC TGA GTAA CAT-3' \\
M05 & 5'-GAC GAT GAG TCC TGA GTAA CTA-3' \\
M06 & 5'-GAC GAT GAG TCC TGA GTAA CTC-3' \\
M07 & 5'-GAC GAT GAG TCC TGA GTAA CTG-3' \\
M08 & 5'-GAC GAT GAG TCC TGA GTAA CTT-3' \\
\hline
\end{tabular}


The following protocol was used for PCR amplification: 1 cycle at $94^{\circ} \mathrm{C}$ for $30 \mathrm{~s}, 65^{\circ} \mathrm{C}$ for $30 \mathrm{~s}$, and $72^{\circ} \mathrm{C}$ for $60 \mathrm{~s}$; followed by 15 cycles of touchdown PCR in which the annealing temperature was decreased by $0.7^{\circ} \mathrm{C}$ every cycle until a touchdown annealing temperature of $56^{\circ} \mathrm{C}$ was reached. Once this temperature was reached, another 20 cycles were conducted as described above for pre-amplification and the products were rapidly cooled on ice.

The products were analyzed by electrophoresis on a $6 \%(\mathrm{w} / \mathrm{v})$ denaturing polyacrylamide gel. The gel was run at constant power $(50 \mathrm{~W})$. The gel was silver-stained (Creste et al., 2001). Bands showing clear polymorphisms were scored visually as present (1) or absent (0).

\section{Statistical analysis}

To evaluate genetic diversity for the construction of a dendrogram, gels were scored in binary format, where the presence of a band was scored as 1 and its absence as 0 . The binary data were used to compute pairwise similarity coefficients (Jaccard, 1908) and the similarity matrix obtained was subjected to cluster analysis using the unweighted pair-group method with arithmetic average (UPGMA) algorithm on NTSYS-PC, version 1.70 (Rohlf, 1992).

The binary data matrix was subjected to principal coordinate analysis (PCoA) using GenAlEx 6.1 (Peakall and Smouse, 2006). The degree of genetic similarity was determined using the Nei's formula (Nei and Li, 1979). formula:

Allelic polymorphic information content (PIC) was calculated using the following

$$
\mathrm{PIC}=1-\Sigma(\mathrm{Pi}) 2 \text {, }
$$

where $\mathrm{Pi}$ is the proportion of the population carrying the $\mathrm{i}^{\text {th }}$ allele, calculated for each microsatellite locus (Botstein et al., 1980). Marker index (MI) was calculated using the formula described by Powell et al. (1996). MI = PIC x proportion of polymorphic bands. Population genetic analysis was performed using the model for dominant markers with diploid individuals using POPGENE version 1.32 (Yeh et al., 1999) to calculate the effective number of alleles per locus $\left(N_{\mathrm{E}}\right)$, Nei's gene diversity $(h)$, unbiased diversity $(u h)$ (Nei, 1973), and Shannon's information index (I) (Lewontin, 1972).

\section{Analysis of molecular variance (AMOVA)}

The percentage of molecular variance among 10 accessions (male sterile lines) based on their restorer fertile lines (90-110 and 8222) and different population groups was assessed using GENALEX 6 (Peakall and Smouse, 2006). The statistical significance of variances was tested by determining the random permutations with the number of permutations set at 9999 .

\section{RESULTS}

All 64 primer-pair combinations were tested and 13 primer pairs were selected to assay 5 hybrids and their restorer lines (A-90-110 and A-8222) from each of the 2 groups for AFLP marker analysis. A total of 682 scorable bands were detected after selective PCR amplification with all primer combinations (Table 4). The bands ranged in size from 50 to $2000 \mathrm{bp}$. These primer pairs produced 113 polymorphic bands; the results support that the AFLP marker 
system is efficient for genetic diversity analysis (Wu et al., 2000).

\begin{tabular}{|c|c|c|c|c|c|c|}
\hline Sr. No. & $\begin{array}{l}\text { AFLP primer } \\
\text { combination }\end{array}$ & $\begin{array}{l}\text { Total No. of } \\
\text { amplified } \\
\text { bands }\end{array}$ & $\begin{array}{l}\text { No. of polymorphic } \\
\text { bands }\end{array}$ & $\begin{array}{l}\text { Polymorphic } \\
\text { bands (\%) }\end{array}$ & $\begin{array}{l}\text { Polymorphic } \\
\text { information } \\
\text { content }\end{array}$ & $\begin{array}{l}\text { Marker } \\
\text { index }\end{array}$ \\
\hline 1 & E1/M1 & 60 & 11 & 18.333 & 0.332 & 3.649 \\
\hline 2 & E1/M2 & 66 & 10 & 15.152 & 0.324 & 3.239 \\
\hline 3 & E1/M3 & 39 & 16 & 41.026 & 0.239 & 3.832 \\
\hline 4 & E1/M4 & 31 & 14 & 45.161 & 0.215 & 3.009 \\
\hline 5 & E1/M5 & 63 & 4 & 6.349 & 0.361 & 1.443 \\
\hline 6 & E1/M6 & 33 & 12 & 36.364 & 0.248 & 2.970 \\
\hline 7 & E1/M8 & 111 & 3 & 2.703 & 0.470 & 1.410 \\
\hline 8 & $\mathrm{E} 3 / \mathrm{M} 2$ & 48 & 10 & 20.833 & 0.350 & 3.504 \\
\hline 9 & E4/M6 & 18 & 4 & 22.222 & 0.467 & 1.869 \\
\hline 10 & E5/M4 & 90 & 7 & 7.778 & 0.392 & 2.744 \\
\hline 11 & E6/M8 & 47 & 5 & 10.638 & 0.359 & 1.793 \\
\hline 12 & E7/M1 & 39 & 7 & 17.949 & 0.407 & 2.849 \\
\hline 13 & E7/M5 & 37 & 10 & 27.027 & 0.262 & 2.619 \\
\hline Total & & 682 & 113 & & & \\
\hline
\end{tabular}

The AFLP marker dendrogram showing genetic relationships from UPGMA cluster analysis revealed 2 major groups corresponding to their maintainer lines (A-90-110 and A-8222) (Figure 1). This study demonstrated that AFLP is a very sensitive technique for detecting markers in genetic studies of wheat crops. The banding patterns attained using AFLP were found to be highly reproducible when the same sample DNA was used in independent experiments (Pillay and Myers, 1999). Silver staining was used in this study because silverstained AFLP gels are thought to produce a larger number of better-defined bands than phosphorous-32-labeled gels (Cho et al., 1996).

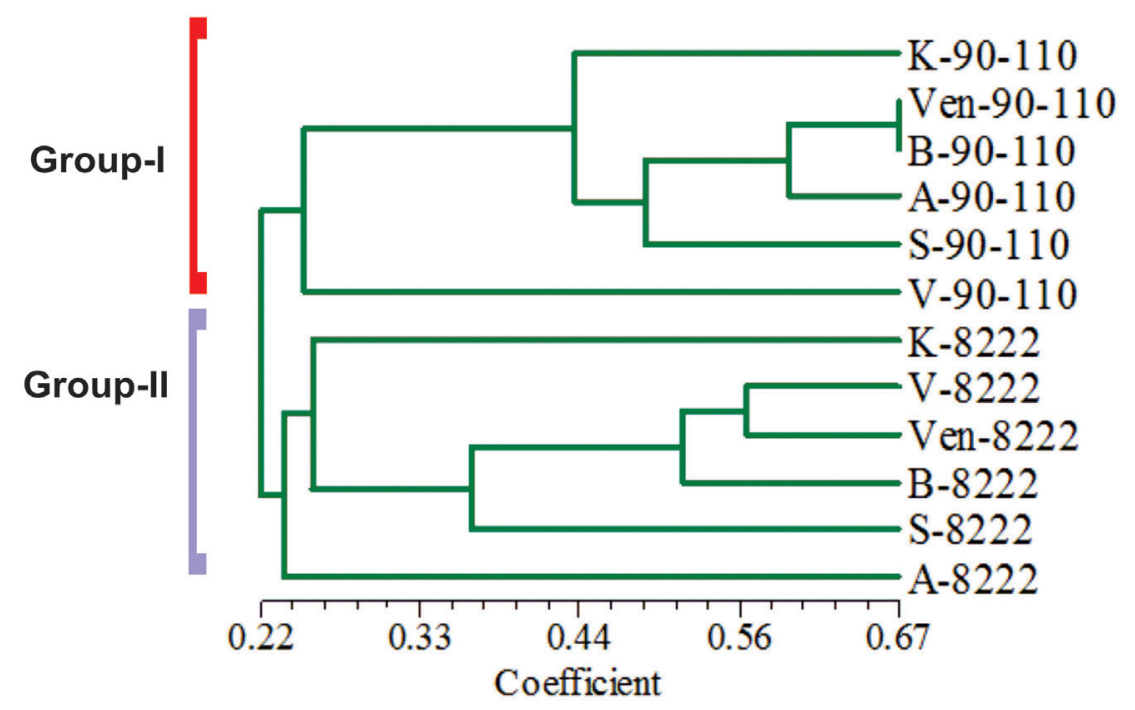

Figure 1. Neighbor joining tree of wheat accessions. Dendrogram tree divided the wheat accessions into 2 groups according to their restorer line. 
A similar structure was revealed by the PCoA. The analyzed specimens formed 2 main groups - I and II, as shown in Figure 2. Two PCoA plots were generated based on the first and second eigenvectors. The figure based on these eigenvectors revealed 2 distinct groups of male sterile lines divided based on their restorer fertile lines, accounting for $28.82 \%$ on PC1 and $24.64 \%$ on PC2 of the total variation.

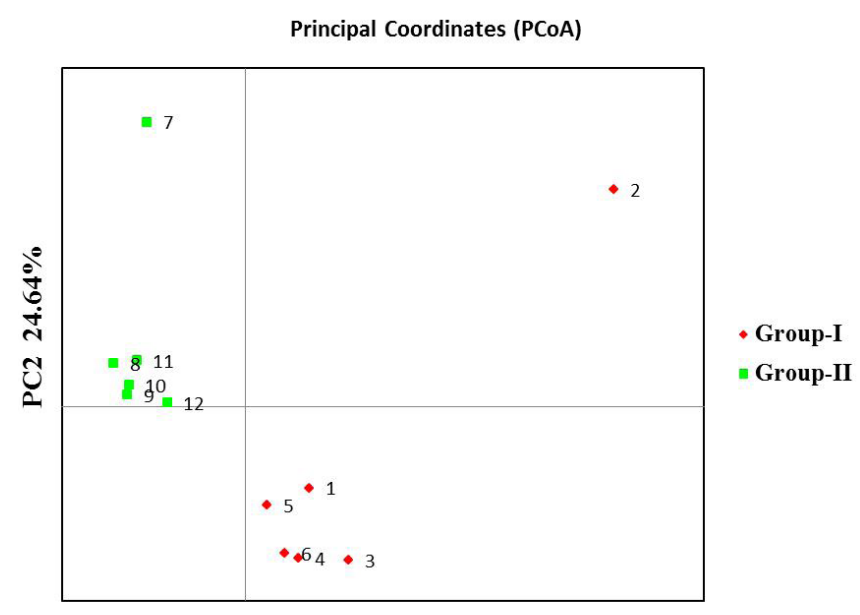

PC1 28.82\%

Figure 2. Principal coordinate analysis ( $\mathrm{PCoA})$ of wheat accessions. The PCoA plot divided wheat accessions into 2 groups based on their maintainer fertile line.

The 13 AFLP marker primer combinations used generated a total of 682 bands, of which $113(16.56 \%)$ were polymorphic among the 12 genotypes analyzed. The PIC values of different primer combinations ranged from 0.215 (primer pair E1/M4) to 0.470 (primer pair E1/M8), while MI values were between 1.41 (primer pair E1/M8) and 3.832 (primer pair E1/M3).

The mean $N_{\mathrm{E}}$ varied from 1.257 to $1.459, I$ ranged from 0.254 to $0.407, h$ varied from 0.164 to 0.267 , and $u h$ from 0.197 to 0.320 in AFLP marker combinations (Table 5).

\begin{tabular}{|c|c|c|c|c|c|}
\hline Sr. No. & $\begin{array}{l}\text { AFLP marker } \\
\text { primer combination }\end{array}$ & $\begin{array}{l}\text { No. of effective } \\
\text { alleles }\end{array}$ & $\begin{array}{c}\text { Shannon's } \\
\text { information index }\end{array}$ & $\begin{array}{l}\text { Genetic } \\
\text { diversity }\end{array}$ & $\begin{array}{l}\text { Unbiased genetic } \\
\text { diversity }\end{array}$ \\
\hline 1 & E1/M1 & 1.298 & 0.295 & 0.191 & 0.229 \\
\hline 2 & E1/M2 & 1.351 & 0.351 & 0.227 & 0.272 \\
\hline 3 & E1/M3 & 1.273 & 0.266 & 0.173 & 0.207 \\
\hline 4 & E1/M4 & 1.258 & 0.268 & 0.171 & 0.205 \\
\hline 5 & E1/M5 & 1.431 & 0.407 & 0.267 & 0.320 \\
\hline 6 & E1/M6 & 1.315 & 0.308 & 0.200 & 0.240 \\
\hline 7 & E1/M8 & 1.459 & 0.381 & 0.261 & 0.313 \\
\hline 8 & E3/M2 & 1.268 & 0.291 & 0.183 & 0.220 \\
\hline 9 & E4/M6 & 1.257 & 0.254 & 0.164 & 0.197 \\
\hline 10 & E5/M4 & 1.333 & 0.320 & 0.209 & 0.251 \\
\hline 11 & E6/M8 & 1.328 & 0.314 & 0.206 & 0.247 \\
\hline 12 & E7/M1 & 1.300 & 0.324 & 0.205 & 0.245 \\
\hline 13 & E7/M5 & 1.288 & 0.285 & 0.185 & 0.222 \\
\hline
\end{tabular}


The total mean values (group I and group II) of $N_{\mathrm{E}}, I, h$, and $u h$ were 1.319, 0.311, 0.202, and 0.243 , respectively (Table 6).

AMOVA was partitioned, and the total AFLP variation in within- and among-accession components is summarized in Table 7 . AMOVA showed that $77 \%$ of the total variation was present in the within-group population and 23\% among the 2 group accessions (Figure 3).

Table 6. Mean genetic diversity of wheat accessions based on AFLP markers.

\begin{tabular}{cccccc}
\hline Group & $\begin{array}{c}\text { AFLP marker } \\
\text { primer combination }\end{array}$ & $\begin{array}{c}\text { No. of effective } \\
\text { alleles }\end{array}$ & $\begin{array}{c}\text { Shannon's information } \\
\text { index }\end{array}$ & $\begin{array}{c}\text { Genetic } \\
\text { diversity }\end{array}$ & $\begin{array}{c}\text { Unbiased genetic } \\
\text { diversity }\end{array}$ \\
\hline 1 & Mean & 1.310 & 0.300 & 0.195 & 0.234 \\
2 & Mean & 1.328 & 0.322 & 0.209 & 0.251 \\
Total & Mean & 1.319 & 0.311 & 0.202 & 0.243 \\
\hline
\end{tabular}

Table 7. Analysis of molecular variance (AMOVA) results of wheat accessions.

\begin{tabular}{lrrrrrr}
\hline Source & d.f. & \multicolumn{1}{c}{ SS } & MS & Est. var. & $\%$ Var. & P value \\
\hline Among group & 1 & 80.667 & 80.667 & $8.694^{* *}$ & $23 \%$ & 0.010 \\
Within group & 10 & 285.000 & 28.500 & $28.500^{* *}$ & $77 \%$ & $100 \%$ \\
Total & 11 & 365.667 & & 37.194 & \\
\hline
\end{tabular}

**Significant difference at $1 \%$ level.

\section{Percentages of Molecular Variance}

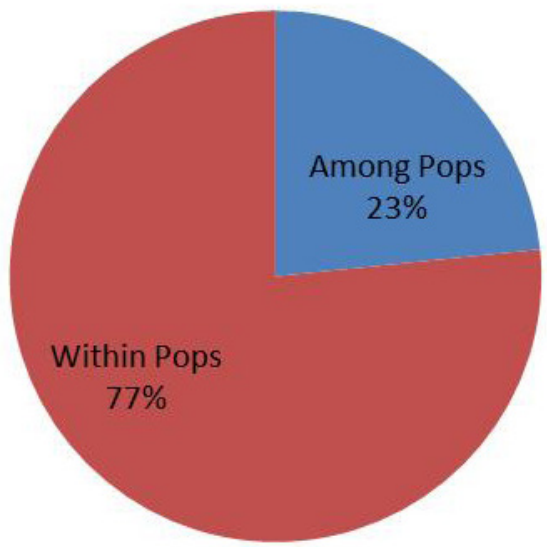

Figure 3. Analysis of molecular variance (AMOVA) of wheat accessions. Molecular analysis divided wheat accessions into 2 groups.

\section{DISCUSSION}

Effectual utilization of the genetic potential in the germplasm collections requires an understanding of the genetic diversity present in the collected material. Knowledge regarding 
plant trait variability and the association of specific traits with hybridization not only facilitates breeding programs but also helps to design future germplasm collections. Molecular data have played a vital role in understanding the genetic relationships among various plants and have led to new genetic classifications that often conflict with traditional taxonomy (Jobst et al., 1998). Genotypes provide valuable information for improving breeding programs and germplasm resource management (Roldán-Ruiz, 2001). The primary aim of this study was to identify supplementary and valid molecular markers suitable for examining genetic diversity in order to assess genetic relationships in 10 male sterile lines of wheat. The goal was to obtain useful molecular data regarding the local gene pool. Wheat genotypes have been analyzed using different DNA marker systems and have identified genetic diversity or similarity levels within a specific group of genotypes (Eujay et al., 2001).

AFLP marker analysis is useful for identifying polymorphic molecular markers in this population complex, and a total of 113 polymorphic AFLP fragments were obtained from 13 primer combinations in this study. A low level of polymorphism has been observed in wheat (Reif et al., 2005). The low level of polymorphism was reported to be an average of 10 alleles per locus in emmer wheat (Fahima et al., 1998). Cluster analysis was based on Jaccard's similarity estimates (Jaccard, 1908). Using different DNA marker systems, wheat genotypes from the same origin have been analyzed, revealing genetic diversity or similarity levels within a specific group of genotypes (Eujay et al., 2001). Hybrid wheat line V-90-110 (group I) and K-8222 (Group II) showed the largest differences among the materials studied (Figure 1). Wheat male sterile lines were equally dispersed with their maintainer fertile line (A-90-110 and A-8222) in each group. The arrangement of male sterile lines on the dendrogram can be explained by affinity in pedigree, as in the case of pairs V-90-110 vs A-90-110 and K-8222 vs A-8222. The bootstrap procedure performed on binary data indicated that V-90-110 and K-8222 significantly differed from other lines. Population variability is related to reproduction methods. This has been observed in numerous species and supports the positive association between the amount of outcrossing and genetic variation. In general, autogamous species show greater differences among, rather than within, populations (Charlesworth and Charlesworth, 1995).

PCoA is a multivariate approach for grouping based on similarity coefficients or variance-covariance among traits. This method provides information regarding differentiation among major groups, while cluster analysis provides higher resolution among closely related populations. PCoA based on Gower's similarity coefficient (Gower, 1966) revealed relationships among the accessions in 2-dimensional spaces. PCoA revealed a similar structure. The analyzed specimens formed 2 main groups, I and II, as shown in Figure 2, and 2 PCoA plots were generated based on the first-second eigenvectors. The figure based on this eigenvectors revealed 2 distinct groups into which the male sterile lines were divided based on their restorer fertile lines, accounting for $28.82 \%$ in $\mathrm{PC} 1$ and $24.64 \%$ in $\mathrm{PC} 2$ of the total variation. The AFLP marker method appears to be more effective for generating genotype-specific bands (Degani et al., 2001). Pre-digesting the template DNA before the PCR resulted in broadening the level of detected polymorphisms (Riede et al., 1994), suggesting that the presented method is auspicious for effective cultivar identification. The PCoA plot agreed well with the results of UPGMA cluster analysis. In contrast, the genetic relationships among hybrid-related populations were better visualized by PCoA.

The 13 AFLP marker primer combinations used generated a total of 682 bands, of which $113(16.56 \%)$ were polymorphic among the 12 genotypes examined. PIC values for different primer combinations ranged from 0.215 to 0.470 . The lowest and the highest PIC 
values were observed for primers E1/M4 and E1/M8, respectively. PIC values and MI were nearly the same as those published by Manifesto et al. (2001) in wheat. PIC values were very similar to the primer combinations used, and thus higher MI values were detected for combinations presenting a higher number of polymorphic bands. The combination producing the largest number of polymorphic bands (16 bands) was E1/M3 (MI value was 3.832), while the combination producing the lowest number of polymorphic bands ( 3 bands) was E1/M8 (MI value was 1.410 ). The polymorphic bands (113 bands) obtained using all primer combinations demonstrated that AFLP analysis can be used to detect genetic variability present in these wheat genotypes. Corbellini et al. (2002) reported that when 40 wheat genotypes from Central and Southern Europe were examined using 5 AFLP primer combinations, an average of 40 polymorphic bands per primer combination, and a total of 200 polymorphic bands were obtained. Slightly lower levels of polymorphism have been detected in wheat, such as the 59\% determined by Almanza-Pinzón et al. (2003) and the 47\% reported by Roy et al. (2004). Marker attributes such as PIC and MI have been used in several studies to assess AFLP markers for genetic diversity analysis (Leelambika et al., 2010). These studies have found that AFLP markers are efficient for detecting genetic variability in wheat. Diversity analysis can be used to decode genetic relationships and is useful for efficiently managing germplasms (Al-Doss et al., 2011). The environment has no effect on molecular diversity and can be estimated by DNA obtained from germplasm at any growth stage (Tatikonda et al., 2009).

Nei's gene diversities $(h)$ varied from 0.164 to 0.267 , unbiased $(u h)$ diversity from 0.197 to 0.320 , and Shannon's indices $(I)$ ranged from 0.254 to 0.407 . Additionally, the values for $h$ and $I$ showed a similar trend. The mean effective alleles $\left(N_{\mathrm{E}}\right)$ varied from 1.257 to 1.459. Among the 13 AFLP marker primer combinations, E1/M5 showed the highest genetic variation and E4/M6 showed the lowest genetic variation. The total mean values (group I and group II) of $N_{\mathrm{E}}, I, h$, and $u h$ were found to be $1.319,0.311,0.202$, and 0.243 , respectively. Shannon's information index agreed with the results of Xie et al. (2010). Shannon's information index was calculated to provide a relative estimate of the degree of variation within genotypes (Lewontin, 1972).

AMOVA was used to determine the total AFLP variation into within- and amongaccession components (Table 7). AMOVA revealed that $77 \%$ of the total variation was extant within the group population and 23\% among the 2 group's accessions (Figure 3 ). The results exhibited significant variation among and within the group population. Variation within accessions (77\%) due to the male sterile lines (hetero-cytoplasm with same nucleus) was determined after a number of recurrent backcrosses and the variability among the 2 groups because of their restorer lines (A-90-110 and A-8222). These results agree with those of Zhao et al. (2010).

\section{CONCLUSIONS}

Thirteen AFLP marker primer combinations used to study 10 hybrid male sterile lines (hetero-cytoplasm with the same nucleus) of wheat were used to separate genotypes, yielding 682 bands, of which 113 were polymorphic (16.4\%). The average number of polymorphic bands per AFLP primer combination was 8.69 and the size of AFLP fragments generated by different primer combinations ranged from 50 to $1000 \mathrm{bp}$. Among all primer combinations, E1/M4 showed the highest percentage of polymorphism (45.16\%), while E1/M8 showed the lowest percentage of polymorphism $(2.70 \%)$. The highest un- 
biased genetic diversity (0.32) was observed for the primer combination E1/M5 and the lowest (0.197) by E4/M6.

Therefore, these markers were useful for evaluating genetic diversity among and within species. An advantage of AFLP markers in the study of conservation genetics is that the primers developed for one species are relevant to related taxa. The magnitude and pattern of genetic variation observed in this study will be useful for germplasm supervision and planning of effective-breeding programs.

\section{ACKNOWLEDGMENTS}

Research supported by the National High Technology Research and Development Program of China (\#2011AA10A106), the National Support Program of China (\#2015BAD27B01), the National Natural Science Foundation of China (\#31371697, \#31171611) and the Technological Innovation and Over Planning Projects of Shaanxi Province (\#2014KTZB02-01-02).

\section{REFERENCES}

Al-Doss AA, Saleh M, Moustafa KA, Elshafei AA, et al. (2011). Comparative analysis of diversity based on morphoagronomic traits and molecular markers in durum wheat under heat stress. Afr. J. Biotechnol. 10: 3671-3681.

Almanza-Pinzón MI, Hairallah M, Fox PN and Walburton ML (2003). Comparison of molecular markers and coefficients of parentage for the analysis of genetic diversity among spring bread wheat accessions. Euphytica 130: 77-86.

Arzani A, Poursiahbidi M and Rezai A (2000). Influences of durum wheat and Aegilops genotypes on the production of haploid plants. Iran Agric. Res. 19: 49-62.

Botstein D, White RL, Skolnick M and Davis RW (1980). Construction of a genetic linkage map in man using restriction fragment length polymorphisms. Am. J. Hum. Genet. 32: 314-331.

Charlesworth D and Charlesworth B (1995). Quantitative genetics in plants: the effect of the breeding system on genetic variability. Evaluation 49: 911-920.

Cho, Blair MW, Panaud O and McCouch SR (1996). Cloning and mapping of variety-specific rice genomic DNA sequences: amplified fragment length polymorphisms (AFLP) from silver-stained polyacrylamide gels. Genome 39: 373-378.

Corbellini M, Perenzin M, Accerbi M, Vaccino P, et al. (2002). Genetic diversity in bread wheat, as revealed by coefficient of parentage and molecular markers, and its relationship to hybrid performance. Euphytica 123: 273-285.

Creste S, Tulmann NA and Figueira A (2001). Detection of single sequence repeat polymorphisms in denaturing polyacrylamide sequencing gels by silver staining. Plant Mol. Biol. Rep. 19: 299-306.

Degani C, Rowland LJ, Saunders JA, Hokanson SC, et al. (2001). A comparison of genetic relationship measures in strawberry (Fragaria x ananassa Duch.) based on AFLPs, RAPDs, and pedigree data. Euphytica 117: 1-12.

Doyle JJ and Doyle JL (1990). Isolation of plant DNA from fresh tissue. Focus 12: 13-15.

Eujay I, Sorrells M, Baum M, Woltersand P, et al. (2001). Assessment of genotypic variation among cultivated durum wheat based on EST-SSRs and genomic SSRs. Euphytica 119: 39-43.

Fahima T, Röder M, Grama A and Nevo E (1998). Microsatellite DNA polymorphism divergence in Triticum dicoccoides accessions highly resistant to yellow rust. Theor. Appl. Genet. 96: 187-195.

Gowda M, Kling CK, Würschum T, Liu W, et al. (2010). Hybrid breeding in durum wheat: heterosis and combining ability. Crop Sci. 50: 2224-2230.

Gower JC (1966). Some distance properties of latent root and vector methods used in multivariate analysis. Biometrica 53: 325-338

Jaccard P (1908). Nouvelles recherches sur la distribution florale. Bull. Soc. Vaudoise Sci. Nat. 44: 223-270.

Jasieniuk M and Maxwell BD (2001). Plant diversity: new insights from molecular biology and genomics technologies. Weed Sci. 49: 257-265.

Jobst J, King K and Hemlebeh V (1998). Molecular evolution of internal transcribed spacers (ITS1 and ITS2) and phylogenetic relationships among species of the family Cucurbitaceae. Mol. Phylogenet. Evol. 9: 204-219. 
Lee M (1995). DNA markers and plant breeding programs. Adv. Agron. 55: 265-344.

Leelambika M, Mahesh S, Jaheer M and Sathyanarayana N (2010). Comparative evaluation of genetic diversity among Indian Mucuna species using morphometric, biochemical and molecular approaches. World J. Agric. Sci. 6: 568-578.

Lewontin RC (1972). The apportionment of human diversity. Evol. Biol. 6: 381-398.

Manifesto MM, Schlatter AR, Hopp HE, Suarez HE, et al. (2001). Quantitative evaluation of genetic diversity in wheat germplasm using molecular markers. Crop Sci. 41: 682-690.

Mueller UG and Wolfenbarger LL (1999). AFLP genotyping and finger printing. Trends Ecol. Evol. 14: 389-394.

Nei M (1973). Analysis of gene diversity in subdivided populations. Proc. Natl. Acad. Sci. U S A 70: 3321-3323.

Nei M and Li WH (1979). Mathematical model for studying genetic variation in terms of restriction endonucleases. Proc. Natl. Acad. Sci. U S A 76: 5269-5273.

Peakall R and Smouse PE (2006). GenAlEx 6: genetic analysis in Excel. Population genetic software for teaching and research. Mol. Ecol. Not. 6: 288-295.

Pillay M and Myers GO (1999). Genetic diversity in cotton assessed by variation in ribosomal RNA genes and AFLP markers. Crop Sci. 39: 1881-1886.

Powell W, Morgante M, Andre C, Hanafey M, et al. (1996). The comparison of RFLP, RAPD, AFLP and SSR (microsatellite) markers for germplasm analysis. Mol. Breed. 2: 225-238.

Reif JC, Zhang P, Dreisigacker S, Warburton ML, et al. (2005). Wheat genetic diversity trends during domestication and breeding. Theor. Appl. Genet. 110: 859-864.

Riede CR, Fairbanks DJ, Andersen WR, Kehrer RL, et al. (1994). Enhancement of RAPD analysis by restriction endonuclease digestion of template DNA in wheat. Plant Breed. 113: 254-257.

Rohlf FJ (1992). NTSYS-PC: Numerical taxonomy and multivariate analysis system. Exeter Software, New York.

Roldán-Ruiz I, van Eeuwijk FA, Gilliland TJ, Dubreuil P, et al. (2001). A comparative study of molecular and morphological methods of describing relationships between perennial ryegrass (Lolium perenne L.) varieties. Theor. Appl. Genet. 103: 1138-1150.

Roy JK, Lakshmikumaran MS, Balyan HS and Gupta PK (2004). AFLP-based genetic diversity and its comparison with diversity based on SSR Sample and phenotypic traits in bread wheat. Bioc. Gen. 42: 43-59.

Tatikonda L, Wani SP, Kannan S, Beerelli N, et al. (2009). AFLP-based molecular characterization of an elite germplasm collection of Jatropha curcas L., a biofuel plant. Plant Sci. 176: 505-513.

Valkoun JJ (2001). Wheat pre-breeding using wild progenitors. Euphytica 119: 17-23.

Vos P, Hogers R, Bleeker M, van Reijans M, et al. (1995). AFLP: a new technique for DNA fingerprinting. Nucleic Acids Res. 23: 4407-4414.

Wu MS, Wang SC and Dai JR (2000). Application of AFLP markers to heterotic grouping of elite maize inbred lines. Acta Agon. Sin. 26: 9-13.

Xie W, Zhang X, Cai H, Liu W, et al. (2010). Genetic diversity analysis and transferability of cereal EST-SSR markers to orchard grass (Dactylis glomerata L.). Biochem. Syst. Ecol. 38: 740-749.

Yadav HK, Shukla S and Singh PS (2007). Genetic divergence in parental genotypes and its relation with heterosis, F1 performance and general combining ability (GCA) in opium poppy (Papaver somniferum L.). Euphytica 157: 123130.

Yeh FC, Yang RC, Boyle T, Ye ZH, et al. (1999). POPGENE, the user friendly shareware for population genetic analysis. Molecular Biology and Biotechnology Centre. University of Alberta, Edmonton.

Zhao W, Chung J, Cho Y, Rha W, et al. (2010). Molecular genetic diversity and population structure in Lycium accessions using SSR markers. C. R. Biol. 333: 793-800. 